$\underline{\text { Research article }}$

\title{
A preliminary study of $m e c A$ gene expression and methicillin resistance in staphylococci isolated from the human oral cavity
}

\author{
WMDA Wijesundara ${ }^{1}$, RGSC Rajapakse ${ }^{1}$, \\ JAMA Jayatilake ${ }^{2}$, JAMS Jayatilake ${ }^{3}$ \\ Sri Lankan Journal of Infectious Diseases 2019 Vol. 9(1):42-48 \\ DOI: http://dx.doi.org/10.4038/sljid.v9i1.8232
}

\begin{abstract}
Introduction: Staphylococci are common human commensals that acquire methicillin resistance via the $m e c A$ gene. Methicillin resistance in staphylococci from various clinical sources has been assessed using cefoxitin disc diffusion test (CDDT) and PCR detection of the mecA gene. However, oral staphylococci have been studied less frequently compared with other clinical sources. There are no previous studies on methicillin resistance in oral staphylococci in Sri Lanka.
\end{abstract}

Objective: This study aimed to demonstrate methicillin resistance in staphylococci isolated from the human oral cavity using CDDT and PCR detection of mecA gene.

Materials and methods: Twenty-five oral isolates of staphylococci were selected after confirming their identity using colony morphology, Gram stain, catalase test, and the coagulase test. Further authentication of identity was obtained using amplification of the 16S rRNA gene. Methicillin resistance was demonstrated using CDDT and PCR detection of the mecA gene.

Results: There were 7 (28\%) isolates of coagulase positive (presumed S. aureus) and $18(72 \%)$ of coagulase negative staphylococci (CoNS). All the coagulase positive isolates were methicillin sensitive. Within the $18 \mathrm{CoNS}, 2$ (11\%) were methicillin resistant and were found to carry the $m e c A$ gene using PCR.

Conclusion: Coagulase positive and negative staphylococci with or without methicillin resistance may colonize the human oral cavity. Coagulase negative staphylococci were the majority in this limited study. Further studies are warranted to

${ }^{1}$ Faculty of Science, University of Peradeniya, Peradeniya, Sri Lanka
${ }^{2}$ Ministry of Health, Colombo, Sri Lanka,
${ }^{3}$ Faculty of Dental Sciences, University of Peradeniya, Peradeniya, Sri Lanka.
Address for correspondence: Professor J.A.M.S. Jayatilake, Faculty of Dental Sciences, University of
Peradeniya, Peradeniya, Sri Lanka. Telephone: +94812397246 Email: sumedhaj@pdn.ac.lk
(D) https://orcid.org/0000-0003-3961-4133 Received 23 October 2018 and revised version accepted 3 February 2019

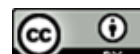

This an open-access article distributed under the terms of the Creative Commons Attribution License, which permits unrestricted use, distribution, and reproduction in any medium, provided the original author and source are credited. 
determine the incidence of staphylococci in the oral cavity and their antimicrobial sensitivity.

Key words: mecA gene, Methicillin resistance, Oral cavity, Staphylococci

\section{Introduction}

Staphylococci are important human commensals inhabiting the skin, nasal mucosa and the oral mucosa. ${ }^{1-4}$ Staphylococci are notorious opportunistic pathogens that are responsible for the majority of hospital acquired infections worldwide. ${ }^{5,6}$ While $S$. aureus is the leading pathogenic species, other species of coagulase negative staphylococci (CoNS) have also emerged as pathogens, especially in immunocompromised patients and patients with prosthetic devices. ${ }^{7}$

Several investigations support the fact that staphylococci are human oral colonizers both in health and disease. For instance, staphylococci have been abundantly isolated from the subgingival biofilm collected from patients with chronic periodontitis as well as from healthy individuals. ${ }^{8-10} \mathrm{~A}$ recent analysis of subgingival biofilm collected from patients with chronic periodontitis as well as from healthy individuals identified both $S$. aureus and CoNS including $S$. auricularis, $S$. epidermidis and $S$. saprophyticus as oral microorganisms. ${ }^{8}$ Staphylococci are also found to colonize removable partial dentures along with Candida and enteric bacilli. ${ }^{11,12}$

Development of antimicrobial resistance in staphylococci is a serious challenge faced by the clinicians. ${ }^{5,6}$ In addition to the production of beta-lactamase, staphylococci generate antimicrobial resistance through the mecA gene that encodes penicillin binding protein-2a (PBP-2a) responsible for methicillin resistance. ${ }^{13,14}$ PBP-2a has lower affinity for $\beta$-lactam antibiotics compared to the typical penicillin binding protein-2 (PBP2) produced by methicillin susceptible $S$. aureus (MSSA) as it blocks the active site from binding $\beta$ lactams. ${ }^{15,16}$ Consequently, staphylococci which carry chromosomally confined $m e c A$ gene are considered highly virulent due to their resistance to all $\beta$-lactam antibiotics.

Methicillin resistance in staphylococci is often detected by antimicrobial disc diffusion or broth dilution methods whereas detection of the mecA gene by PCR is a rapid and far more reliable technique. ${ }^{17-20}$ Although methicillin resistance in staphylococci isolated from different human sources has been studied extensively, there are very few studies on methicillin resistance in oral staphylococci. ${ }^{9}$ The purpose of this study therefore was to investigate methicillin resistance in oral staphylococci, using the CDDT and PCR for the detection of the mecA gene.

\section{Materials and methods}

\section{Isolates of staphylococci}

A total of 25 Staphylococcus isolates collected from the oral cavities of patients attending the Dental (Teaching) Hospital, Peradeniya, Sri Lanka were used for the study. These isolates were collected in an earlier study during which patients' informed consent was obtained to use such organisms for future research. The isolates 
included 9 samples collected by subgingival plaque sampling and 16 samples collected using the concentrated oral rinse technique. ${ }^{8}$ None of the samples were identifiable by the personal details of the patient. Ethical approval was obtained from the ethics review committee of the Faculty of Dental Sciences, University of Peradeniya.

Freeze-stored bacteria samples were recovered by culture on blood agar at $37{ }^{\circ} \mathrm{C}$ for 24-48 h. Identity of the bacteria was reconfirmed by cultural characteristics on blood agar, Gram stain, catalase and coagulase tests.

\section{Cefoxitin disc diffusion test (CDDT)}

The antibiotic sensitivity of staphylococci was tested using the CDDT following the Clinical and Laboratory Standards Institute (CLSI). ${ }^{21}$ Standard suspensions of bacteria (0.5 McFarland) were prepared and inoculated onto Muller Hinton Agar (MHA) plates. After placing cefoxitin $30 \mu \mathrm{g}$ discs in the center of the plates, they were incubated at $37{ }^{\circ} \mathrm{C}$ for $18-24 \mathrm{~h}$ and the zones of inhibition were measured. For coagulase positive staphylococci ( $S$. aureus), an inhibition zone diameter of $\leq 21 \mathrm{~mm}$ was considered as methicillin resistant and $\geq 22 \mathrm{~mm}$ was considered as methicillin sensitive whereas for CoNS, inhibition zone diameter of $\leq 24 \mathrm{~mm}$ was considered as methicillin resistant and $\geq 25 \mathrm{~mm}$ was considered as methicillin sensitive (CLSI $\left.\mathrm{M} 100^{21}\right)$.

\section{Extraction of DNA}

The species characterization and demonstration of mecA gene in the genomic DNA of staphylococci were performed according to a method described previously with minor modifications. ${ }^{22}$

All 25 staphylococcal isolates, standard isolates of MSSA (ATCC 25923) and MRSA (ATCC 43300) were subjected to DNA extraction. Bacterial DNA was extracted from fresh bacterial cultures grown overnight on blood agar medium. From the fresh bacterial cultures, 3 to 4 loopfuls were harvested into $10 \mathrm{mM}$ TE buffer (10mM Tris$\mathrm{HCl} \mathrm{pH}, 7.5 / 25 \mathrm{mM}$ EDTA) and subsequently washed twice with $10 \mathrm{mM}$ TE buffer. The resultant pellet after centrifugation was suspended in $0.6 \mathrm{ml}$ of $10 \mathrm{mM}$ TE buffer followed by addition of $10-20 \mu \mathrm{l}$ of lysozyme $(50 \mathrm{mg} / \mathrm{ml})$ to the cell suspension and incubated at room temperature for $30 \mathrm{~min}$. The suspension was mixed gently after addition of $20 \mu \mathrm{l}$ of proteinase $\mathrm{K}(10 \mathrm{mg} / \mathrm{ml})$ and $60 \mu 1$ of SDS $(10 \%)$ and the final suspension was incubated at $50{ }^{\circ} \mathrm{C}$ for $1 \mathrm{~h}$. The suspension was then mixed well with $0.6 \mathrm{ml}$ of phenol/chloroform and centrifuged at $13000 \mathrm{rpm}$ for $15 \mathrm{~min}$. $30 \mu \mathrm{l}$ of $5 \mathrm{M}$ $\mathrm{NaCl}$ was added to the aqueous layer extracted from the centrifuged product. This phenol/chloroform step was repeated once more with 10 min centrifugation and the resulting aqueous solution mixed with two volumes of absolute ethanol and centrifuged at $10000 \mathrm{rpm}$ for $5 \mathrm{~min}$. The supernatant was discarded, and the pellet washed with $70 \%$ ethanol. Finally, the DNA pellet was dried and dissolved with 50$100 \mu \mathrm{l}$ of TE buffer and stored at $-20^{\circ} \mathrm{C}$. The quality of the DNA was assessed by electrophoresis in $1 \%$ agarose gel. 


\section{Species characterization and the detection of mecA gene by multiplex PCR}

$16 S$ rRNA gene amplification was performed as an internal control using the primers given in Weisburg et al. ${ }^{23}$ Accordingly, FD1 (5'- AGAGTTTGATCCTGGCTCAG 3') and RD1 (5'- AAGGAGGTGATCCAGCC -3') primers were used to amplify the region of $16 \mathrm{~S} r R N A$ gene with the amplicon size of $1500 \mathrm{bp}$.

For the amplification of mecA gene with the amplicon size of 532bp PCR was performed using the primers described previously. ${ }^{17,22}$ The mecA locus was amplified using forward and reverse primers, (5'-AAAATCGATGGTAAAGGTTGG-3'/5'AGTTCTGCAGTACCGGATTTGC-3') respectively. The amplifications were performed in $15 \mu \mathrm{l}$ reaction volumes each with $5 \mu \mathrm{l}$ of Taq mix (2X GoTaq Green ${ }^{\circledR}$ master mix reaction buffer [pH,8.5] with $400 \mu \mathrm{M}$ dATP, $400 \mu \mathrm{M}$ dATP $400 \mu \mathrm{M}$ dGTP, $400 \mu \mathrm{M}$ dTTP, $400 \mu \mathrm{M} \mathrm{dCTP}$, and $3 \mathrm{mM} \mathrm{MgCl}_{2}$ ), $0.5 \mu 1$ of each primer, 6 ng templates DNA and nuclease free water. The reactions were carried out in a thermal cycler using the following program. Initial denaturation at $94{ }^{\circ} \mathrm{C}$ for $5 \mathrm{~min}$, followed by 35 cycles of $1 \mathrm{~min}$ of denaturation at $94{ }^{\circ} \mathrm{C}, 1 \mathrm{~min}$ of annealing temperature $55^{\circ} \mathrm{C}, 30$ seconds of extension at $72{ }^{\circ} \mathrm{C}$ and final extension at $72{ }^{\circ} \mathrm{C}$ for $10 \mathrm{~min}$. The amplified PCR products were subsequently visualized on $1.5 \%$ agarose gel stained with ethidium bromide $(1 \mu \mathrm{g} / \mathrm{ml})$ for confirmation of PCR amplification. Finally, PCR products were visualized under UV and photographed.

\section{Results}

\section{Identification of staphylococci}

All 25 staphylococcus isolates were Gram positive, catalase positive cocci arranged in clusters. There were 7 (28\%) coagulase positive staphylococcal (presumed S. aureus) isolates and the remaining $18(72 \%)$ were coagulase negative staphylococci (CoNS). 16S rRNA gene amplification results confirmed that all the isolates were staphylococci (Figure1). Both isolates which were identified as methicillin resistant by CDDT demonstrated the mecA gene by PCR whereas the remaining 23 isolates were negative for the $m e c A$ gene (Figure1).

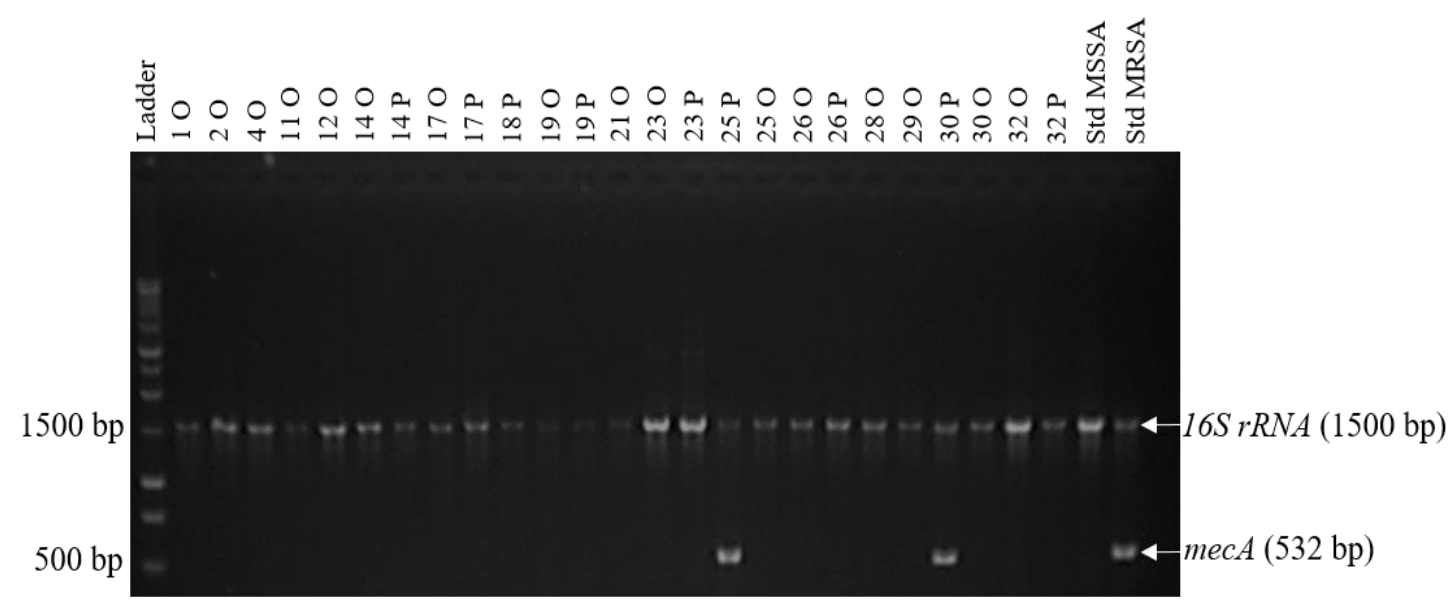

Figure $1 \mathrm{Gel}$ image of the multiplex PCR using primer pairs for the amplification of mecA locus and the internal control $16 S$ rRNA locus, performed on all staphylococcal isolates, standard susceptible and resistant isolates. 


\section{Discussion}

Although staphylococci are known to be frequent colonizers of the oral cavity, the incidence of methicillin resistance in oral staphylococci is poorly studied. ${ }^{1,2,24}$ Hence, the current study investigated methicillin resistance and the responsible mecA gene in oral staphylococci isolated from a group of Sri Lankan patients.

Although a very limited study, the present study showed that the majority (72\%) of oral staphylococci were CoNS supporting the previous findings of Loberto et al. ${ }^{8}$ Only two of the coagulase negative staphylococci and none of the coagulase positive staphylococci in the present study were methicillin resistant. The present study shows that methicillin resistant staphylococci are found in the oral cavity of patients presenting to the Dental (Teaching) Hospital, Peradeniya, Sri Lanka. A retrospective analysis of data relevant to diagnostic oral microbiology in the UK showed that a small proportion $(5 \%)$ of $S$. aureus isolated from oral specimens were MRSA. ${ }^{2}$ However, these investigators did not report on the methicillin resistance of CoNS isolates. In contrast, another study that compared oral colonization of opportunistic pathogens including staphylococci in elderly Japanese patients with oral cancer and a healthy group showed that a large proportion, 9 of 13 oral $S$. aureus $(69.2 \%)$ were MRSA. These investigators also demonstrated that 1 of 9 oral CoNS isolates (11.1\%) were methicillin resistant. ${ }^{25}$ Data obtained in the current study should be carefully interpreted due to the limited number of samples used in the analysis. Further studies using a larger sample would be beneficial to confirm the incidence of oral staphylococci and their antimicrobial resistance.

Both methicillin resistant isolates in the current study were collected from subgingival plaque samples of patients with chronic periodontitis lesions. Although some investigators ${ }^{8-10}$ have isolated staphylococci from the subgingival biofilm collected from patients with chronic periodontitis as well as from healthy individuals, antimicrobial resistance of those staphylococci has not been adequately studied. Therefore, the detection of methicillin resistant isolates in subgingival plaque samples of patients with chronic periodontitis lesions warrants further investigations of antimicrobial resistance in staphylococci associated with periodontitis lesions.

As a phenotypic method for the detection of MR in staphylococci, the disc diffusion test was carried out using cefoxitin which is considered as the most reliable antibiotic for this purpose at present. Multiplex PCR assay was used to demonstrate the mecA gene in staphylococci. It has already been suggested that the detection of mecA gene with PCR offers rapid, simple, and accurate identification of methicillin resistance in staphylococci. ${ }^{19}$ PCR and CDDT corroboration in this very limited study agrees with the previous reports that CDDT is in concordance with the PCR for demonstration of mecA gene. ${ }^{20}$

In conclusion, $S$. aureus and CoNS with or without methicillin resistance may colonize the human oral cavity as discussed above. Therefore, further studies with an increased sample size are warranted to confirm the exact prevalence of methicillin resistance in oral staphylococci. 
Conflicts of interest: There are no conflicts of interest

\section{References}

1. Smith AJ, Jackson MS, Bagg J. The ecology of Staphylococcus species in the oral cavity. J. Med. Microbiol., 2001; 50:940-946. doi: http://dx.doi.org/10.1099/0022-1317-50-11-940

2. Smith AJ, Robertson D, Tang MK, Jackson MS, et al. Staphylococcus aureus in the oral cavity: a three-year retrospective analysis of clinical laboratory data. Br. Dent. J., 2003; 195:701-703. doi: http://dx.doi.org/10.1038/sj.bdj.4810832

3. Kuehnert MJ, Kruszon-Moran D, Hill HA, et al. Prevalence of Staphylococcus aureus nasal colonization in the United States, 2001-2002. J. Infect. Dis., 2006; 193:172179. doi: http://dx.doi.org/10.1086/499632

4. Otto M. Staphylococcus colonization of the skin and antimicrobial peptides. Expert Rev Dermatol. 2010; 5:183-195. doi: http://dx.doi.org/10.1586/edm.10.6

5. Klein E, Smith DL, Laxminarayan R. Hospitalizations and deaths caused by methicillin-resistant Staphylococcus aureus, United States, 1999-2005. Emerg Infect Dis. 2007; 13:1840-1846. doi: http://dx.doi.org/10.3201/eid1312.070629

6. Solberg CO. Spread of Staphylococcus aureus in hospitals: causes and prevention. Scand J Infect Dis. 2000; 32:587-95. doi: http://dx.doi.org/10.1080/003655400459478

7. Becker K, Heilmann C, Peters G. Coagulase-negative staphylococci. Clin Microbiol Rev. 2014; 27: 870-926. doi: http://dx.doi.org/10.1128/CMR.00109-13

8. Loberto JCS, de Paiva Martins CA, dos Santos SSF, et al. Staphylococcus spp. in the oral cavity and periodontal pockets of chronic periodontitis patients. Braz. J. Microbiol., 2004; 35:64-68. doi: http://dx.doi.org/10.1590/S1517-83822004000100010

9. Santos BRM, Demeda CS, Silva EENF, et al. Prevalence of subgingival Staphylococcus at periodontally healthy and diseased sites. Braz. Dent. J., 2014; 25: 271-276. doi: http://dx.doi.org/10.1590/0103-6440201302285

10. Souto R, de Andrade AFB, Uzeda M. Colombo APV. Prevalence of non-oral pathogenic bacteria in subgingival biofilm of subjects with chronic periodontitis. Braz. J. Microbiol., 2006; 37: 208-215. doi: http://dx.doi.org/10.1590/S1517-83822006000300002

11. Daniluk T, Fiedoruk K, Ściepuk M, et al. Aerobic bacteria in the oral cavity of patients with removable dentures. Adv. Med. Sci., 2006; 51: 86-90. No doi

12. Monroy TB, Moreno-Maldonado V, Franco-Martínez F, et al. Candida albicans, Staphylococcus aureus and Streptococcus mutans colonization in patients wearing dental prosthesis. Med. Oral Patol. Oral Cir. Bucal., 2005; 10:27-39. PMID: 15800465

13. Chambers HF. Methicillin resistance in staphylococci: molecular and biochemical basis and clinical implications. Clin. Microbiol. Rev., 1997; 10:781-791. doi: http://dx.doi.org/10.1128/CMR.10.4.781

14. Lyon BR, Skurray R. Antimicrobial resistance of Staphylococcus aureus: Genetic Basis Microbiol Rev., 1987; 5:88-134. No doi

15. Lim D, Strynadka NC. Structural basis for the beta lactam resistance of PBP2a from methicillin-resistant Staphylococcus aureus. Nat. Struct. Mol. Biol., 2002; 9:870-876. doi: https://doi.org/10.1038/nsb858

16. Song MD, Wachi M, Doi M, et al. Evolution of an inducible penicillin-target protein in methicillin-resistant Staphylococcus aureus by gene fusion. FEBS Lett., 1987; 221: 167-171. doi: https://doi.org/10.1016/0014-5793(87)80373-3 
17. Al-Ruaily MA, Khalil OM. Detection of (mecA) gene in methicillin resistant Staphylococcus aureus (MRSA) at Prince A / Rhman Sidery Hospital, Al-Jouf, Saudi Arabia. J. Med. Genet. Genomics. 2011; 3:41-45. No doi

18. Kipp F, Becker K, Peters G, von Eiff C. Evaluation of different methods to detect methicillin resistance in small-colony variants of Staphylococcus aureus. J. Clin. Microbiol., 2004; 42:1277-1279.

doi: http://dx.doi.org/10.1128/JCM.42.3.1277-1279.2004

19. Strommenger B, Kettlitz C, Werner G, Witte W. Multiplex PCR assay simultaneous detection of nine clinically relevant antibiotic resistance genes in Staphylococcus aureus. J. Clin. Microbiol., 2003; 41:4089-4094. doi: http://dx.doi.org/10.1128/JCM.41.9.4089-4094.2003

20. Anand KB, Agrawal P, Kapila K. Comparison of cefoxitin disc diffusion test, oxacillin screen agar, and PCR for mecA gene for detection of MRSA. Indian J. Med. Microbiol., 2009; 27:27-29. PMID: 19172055

21. CLSI. Performance Standards for Antimicrobial Susceptibility Testing. 27th ed. CLSI supplement M100. Wayne, PA: Clinical and Laboratory Standards Institute; 2017. No doi

22. Martineau F, Francois J, Lansac N, et al. Correlation between the resistance genotype determined by multiplex PCR assays and antibiotic susceptibility pattern of Staphylococcus aureus and Staphylococcus epidermidis. Antimicrob. Agents Chemother., 2000; 44:231-238. doi: https://doi.org/10.1128/AAC.44.2.231-238.2000

23. Weisburg WG, Barns SM, Pelletier DA, Lane DJ. 16S ribosomal DNA amplification for phylogenetic study. J. Bacteriol., 1991; 173:697-703. doi: https://doi.org/10.1128/jb.173.2.697-703.1991

24. Costa DM, Kipnis A, Oliveira LSN, et al. Methicillin-resistant Staphylococcus sp. colonizing health care workers of a cancer hospital. Braz. J. Microbiol., 2014; 45: 799-805. doi: http://dx.doi.org/10.1590/S1517-83822014000300006

25. Yamashita K, Ohara M, Kojima T, et al. Prevalence of drug-resistant opportunistic microorganisms in oral cavity after treatment for oral cancer. J. Oral Sci., 2013; 55: 145-155. doi: https://doi.org/10.2334/josnusd.55.145 